\title{
DE WEDEROPSTANDING VAN \\ DRIE SPECTACULAIRE STAPELMANDEN
}

In het depot van het Rijksmuseum bevonden zich sinds jaar en dag drie ivoren stapelmanden - een enkel stuk en een paar - waarvan wel duidelijk was dat het ooit buitengewone eyecatchers waren geweest (afb. 1 en 2). De manden zijn opgebouwd uit zeer dunne paneeltjes van 1 tot 1,5 millimeter die op hun plaats werden gehouden door iets steviger lijsten. Deze lijsten zijn met ingenieuze verbindingen aaneengezet, vastgezet met kleine ivoren pennen. Afgezien van enige dierlijke lijm, bestaan de manden uitsluitend uit ivoor. De panelen zijn ofwel opengewerkt in geometrische patronen, ofwel voorzien van voorstellingen van Chinezen in een landschap tegen een achtergrond van ragfijne stroken ivoor. Tot voor kort verkeerden deze stukken in een tamelijk troosteloze toestand: verbindingen waren losgeraakt zodat ook panelen los zaten, soms vervormd waren en soms los bij de dozen werden bewaard ( $a f b$. 3). In het verleden waren schades aan de panelen aan de binnenzijde met papier verstevigd, papier dat intussen sterk verkleurd was. En al het reliëf en alle lijsten hadden decennialang stof verzameld met als resultaat een algehele grauwheid.

Op foto's van de museumzalen van voor de oorlog is te zien dat de objecten toen tentoongesteld waren bij het Chinese porselein, maar na de oorlog was dit niet het type Chinese kunstnijverheid dat het Rijksmuseum met voorrang aan het publiek wilde laten zien. Toen enige tijd geleden de bescheiden groep Chinese ivoren in het Rijksmuseum onder de loep werden genomen, werd echter duidelijk dat juist deze stapeldozen wel degelijk van belang zijn: vergelijkbare stukken bleken voor te komen in de collectie van het Palace Museum in Taiwan en in vorstelijke Europese collecties waar ze als diplomatiek geschenk waren binnengekomen. ${ }^{1}$ Van het paar ivoren stapelmanden in het Rijksmuseum bleek het bovendien mogelijk de herkomstgeschiedenis tot de eerste eigenaar terug te voeren. Dat bleek Hans Jacob Swarth te zijn, firmant van het handelshuis Insinger, dat in 1814, net na de Franse tijd, het eerste schip had gefinancierd dat in China een lading thee inkocht voor de Nederlandse markt. Economisch en symbolisch was dit herstel van de theehandel van zeer grote betekenis en de schenking van '2 Kunstig gewerkte Vaasen of Werkmandjes' door Swarth aan koning Willem I moest dit succes tot uitdrukking brengen. Willem I was als vorst niet alleen de belichaming van het herstelde Nederland, maar ook de man die aan de economische touwtjes trok en grote invloed had op de commerciële mogelijkheden van mensen als Swarth. Een opzienbarend relatiegeschenk loonde dus zeker de moeite en deze dozen behoorden tot de meest voyante Chinese sierobjecten die op dat moment voorhanden waren.

Afbeelding 1 Stapelmand, ivoor met twee beschilderde medaillons, h. $47 \mathrm{~cm}$., China, 1795-1810, Rijksmuseum, inv.nr. AK-NM-7023
Van de oude luister was, zoals gezegd, niet veel meer over voordat met de restauratie begonnen werd. Een belangrijke, maar niet eenvoudige opgave was de voorwerpen schoon te maken. Allereerst moest de vraag beantwoord 


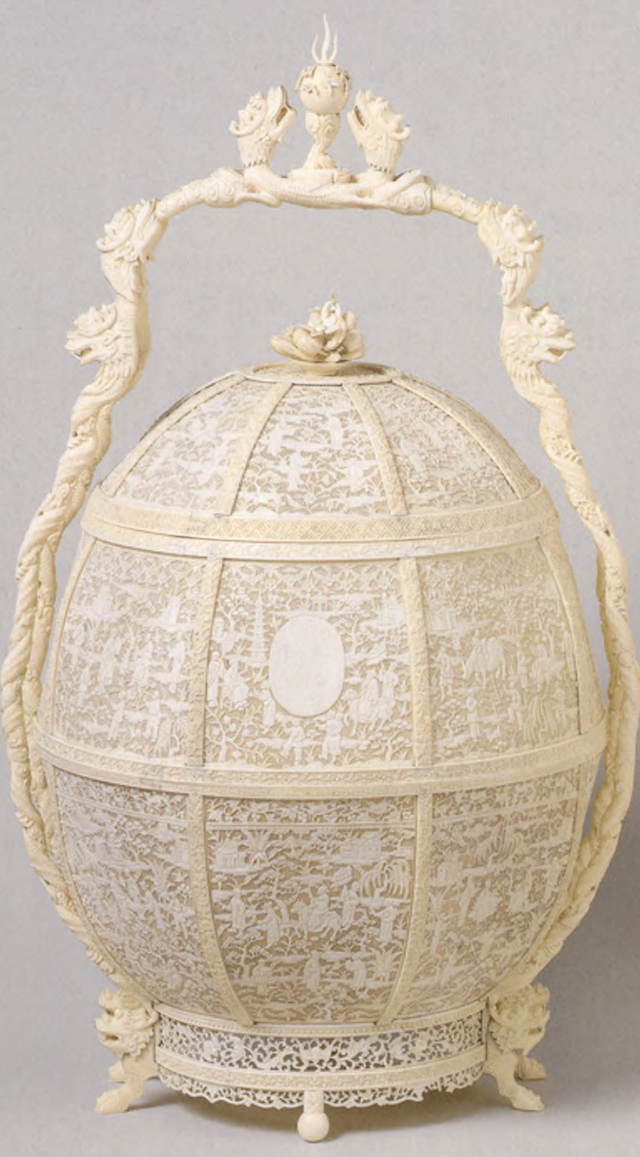

Afbeelding 2 Een paar stapelmanden, ivoor, h. $52 \mathrm{~cm}$., China, ca. 1814, Rijksmuseum, inv.nr. AK-NM-7006-A/B worden hoe schoon de objecten zouden moeten worden. Zo schoon mogelijk biedt een onnatuurlijke aanblik ('het lijkt wel plasticl'), en bovendien wordt de leesbaarheid van de voorstellingen in reliëf minder als alle vervuiling, ook uit de diepste delen verdwenen is. Tot slot is het nauwelijks mogelijk het snijwerk op alle plekken volledig schoon te maken en is het vooral van belang dat het geheel een evenwichtige indruk maakt. Er moest dus een middenweg gekozen worden. Om het vuil zo goed mogelijk te kunnen verwijderen, is een groot deel van de constructie uit elkaar genomen (afb. 4). Met een zachte borstel kon het eerste vuil verwijderd worden, bij het vervolg van het schoonmaken werd kunstmatig saliva (speeksel) gebruikt, een enzymhoudende vloeistof. Het was van belang niet te veel vocht te gebruiken - hierdoor zou het ivoor uitzetten. Tot slot werd het ivoor afgenomen met een ethanoloplossing waarbij weer voorzichtigheid geboden was, aangezien te veel ethanol broosheid kan veroorzaken bij ivoor. Verschillende middelen en samenstellingen waren eerst op stukjes ivoor en vervolgens op minder zichtbare plekken van het object uitgeprobeerd. Er is overwogen voor het 
reinigen een laserpistool te gebruiken, maar daarvan is afgezien. In deze techniek wordt gebruik gemaakt van het verschil in kleur, in dit geval tussen het ivoor en het vuil. Omdat delen van het ivoor echter nogal sterk verkleurd waren (ivoor dat geen daglicht ziet wordt donker), bestond het gevaar dat deze donkere delen samen met het vuil door de laserstraal zouden worden 'weggeschoten'.

De panelen die vervormd waren, werden vochtig gemaakt, voorzichtig in de juiste vorm gebracht en geleidelijk gedroogd. Gebroken en kwetsbare delen werden aan de achterzijde versterkt met glasvezel of Japans papier. Hiervoor werd een acryllijm gebruikt waarvan bekend is dat deze ook na jaren zijn functie goed vervult (zonder te verkleuren en te verharden) en een vergelijkbare flexibiliteit heeft als ivoor. Waar nodig werden aanvullingen gemaakt, ofwel van ivoor, ofwel van een synthetisch materiaal. De kleine ivoren aanvullingen werden in de juiste maat en vorm gesneden, zonder de decoratie over te nemen. Zeer kleine missende delen werden in de juiste kleur en transparantie bijgemaakt in materialen afkomstig uit de hedendaagse tandartspraktijk. Deze aanvullingen betroffen de lijsten en de handvatten van de manden. Maar ook delen van de opengewerkte panelen ontbraken. Hiervoor werden kleine mallen gemaakt, afdrukken van ongerepte delen van de panelen die een aanvulling behoefden. In deze mallen werd met een op kleur gebrachte epoxy een stukje van het patroon bijgemaakt. Deze aanvulling werd op maat gesneden en met behulp van Japans papier in het paneel aangebracht $(\mathrm{afb} .5 \mathrm{a}, \mathrm{b}, \mathrm{c})$. Om de toon van de aanvulling precies met de rest van het paneel overeen te laten komen werd de achterzijde tot slot geretoucheerd.

De schoongemaakte en hier en daar aangevulde onderdelen zijn weer in elkaar gezet, losse verbindingen zijn met een natuurlijke lijm (isinglass) weer vastgezet, soms met nieuwe pennen. Schoon en strak zijn de manden van zorgelijke depotstukken weer volwassen museumobjecten geworden.

Losse verbindingen, mand AK-NM-7006-B

Afbeelding 4 Ontmanteling van mand AK-NM-7006-B
De restauratie bood ook de mogelijkheid iets beter te doorgronden hoe dit snijwerk werd gemaakt. Op dit vlak bestond onwetendheid en onbegrip want, zo was de begrijpelijke veronderstelling, de panelen zijn zo dun dat ze onder je handen breken als je gaat proberen ze te bewerken. Door goed te kijken
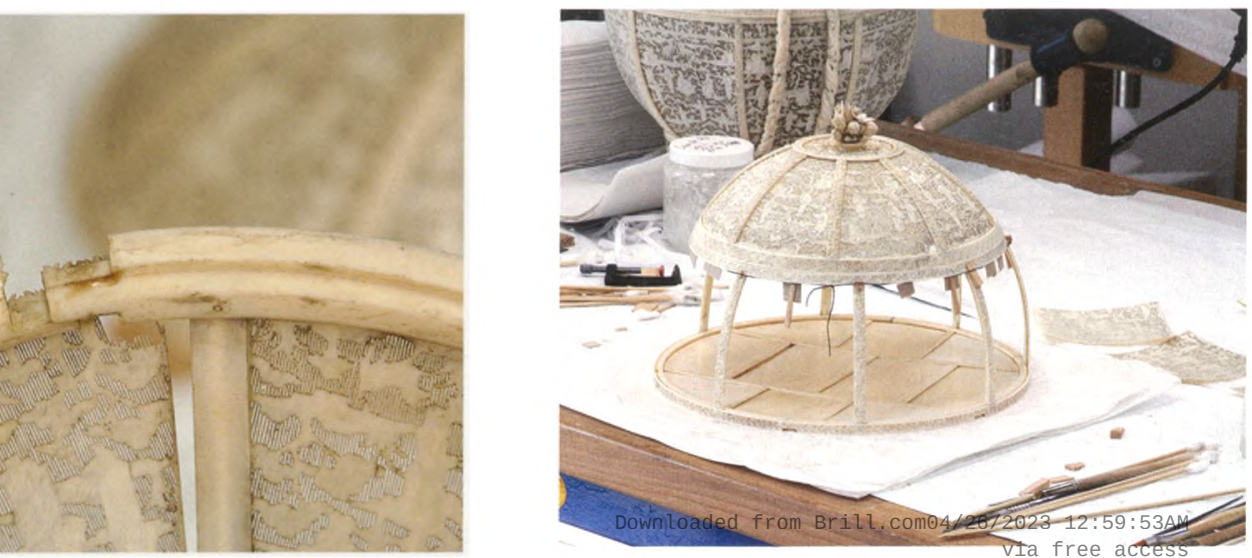

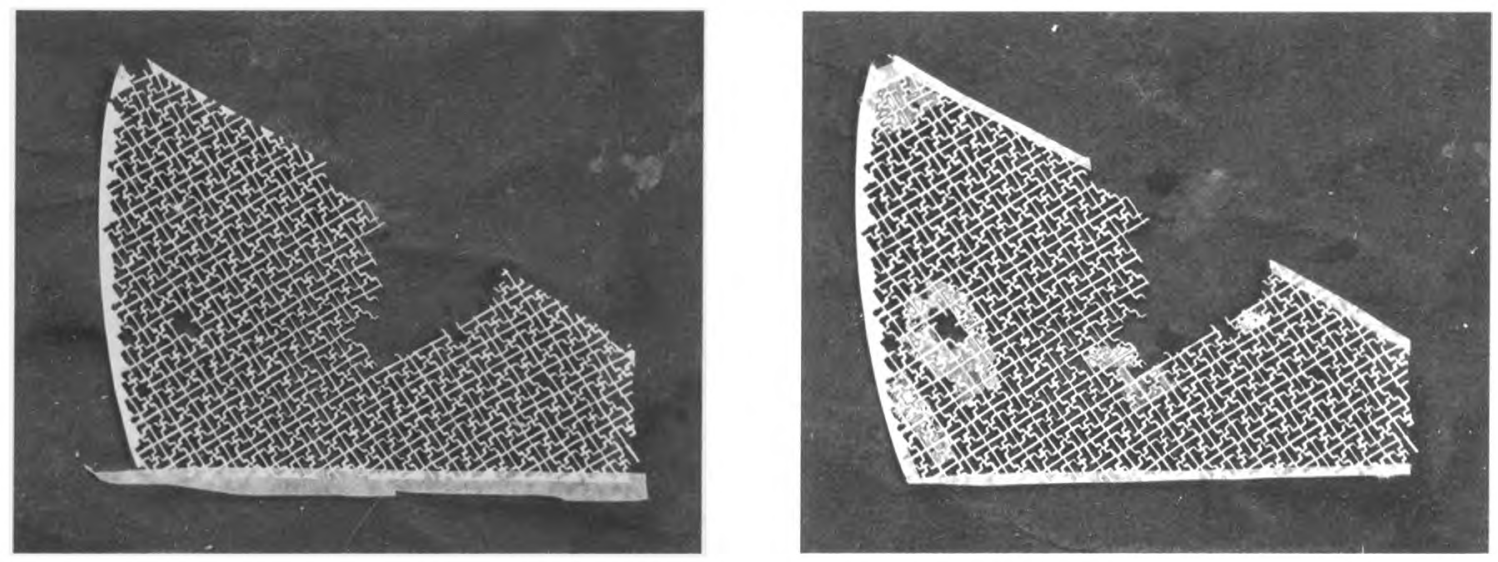

Afbeelding $5 a$ (links) Paneel uit het deksel van mand AK-NM-7023

Afbeelding $5 b$ (midden) Hetzelfde paneel.

De randen zijn versterkt met Japans papier, de zwakke plekken met glasvezel.

Afbeelding $5 \mathrm{C}$ (rechts) Nogmaals hetzelfde paneel, nu met aanvullingen

Afbeelding 6 (onder) Twee verschillende panelen uit mand AK-NM7023 in verschillende stadia van de restauratie met loep en microscoop werden vervaardigingssporen zichtbaar en werd duidelijk dat de figuratieve panelen in reliëf werden uitgesneden in op dat moment nog iets grotere en dikkere stukken ivoor. Schraapsporen aan de achterzijde verraden het gebruik van een schraapmes (drawing knife) om het paneel de juiste dunheid te geven, zaagsporen aan de zijkant het gebruik van een zaag om de panelen op maat te brengen. De opengewerkte lijnen zijn met een burijn ingekrast, om te beginnen vanaf de voorkant. Echt open kreeg de ivoorwerker het paneel op deze manier nog niet, maar dat - zo blijkt uit de burijnsporen - bereikte hij door vervolgens vanaf de achterkant het betreffende deel van het paneel verder open te werken.

Eén fout van de ivoorwerkers verraadde de manier van werken in de andere mand. In verschillende panelen met hetzelfde patroon bleek steeds dezelfde fout op dezelfde plaats terug te keren. Op afbeelding 6 is goed zichtbaar dat men op één plek heeft vergeten te boren (nu zichtbaar als een kleine witte punt). Opvallend is ook dat de beschadiging precies op dezelfde plek zit. Daar is het ivoor te ver weggevijld waardoor de panelen kwetsbaar werden. Dit leidde tot de veronderstelling dat het patroon werd aangebracht door een aantal paneeltjes op elkaar te klemmen en dit pakket als geheel te bewerken.
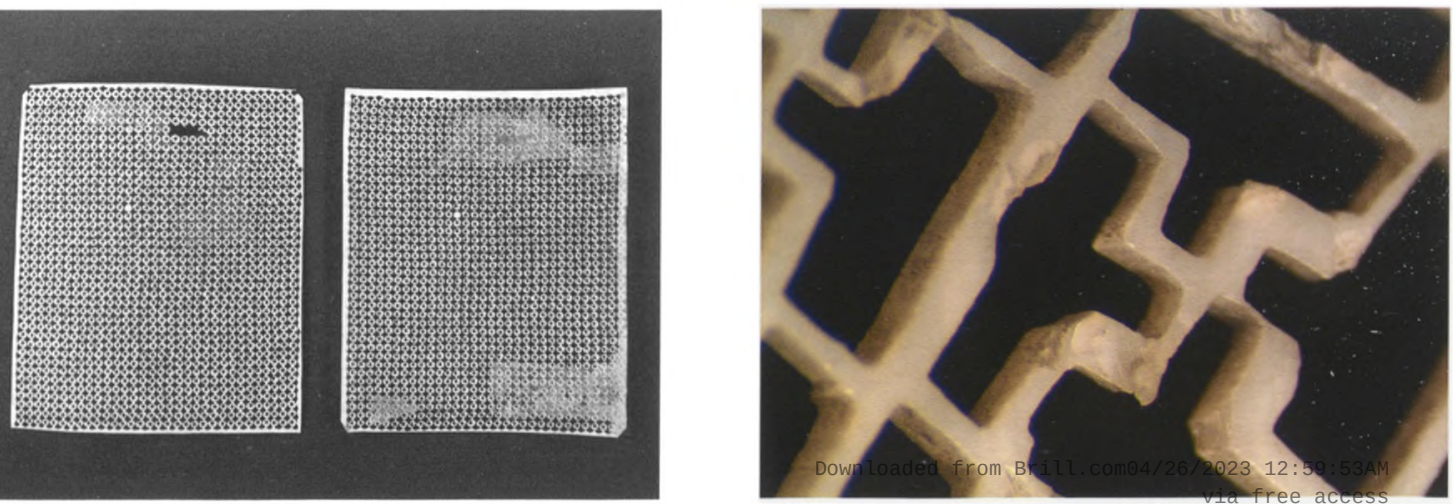


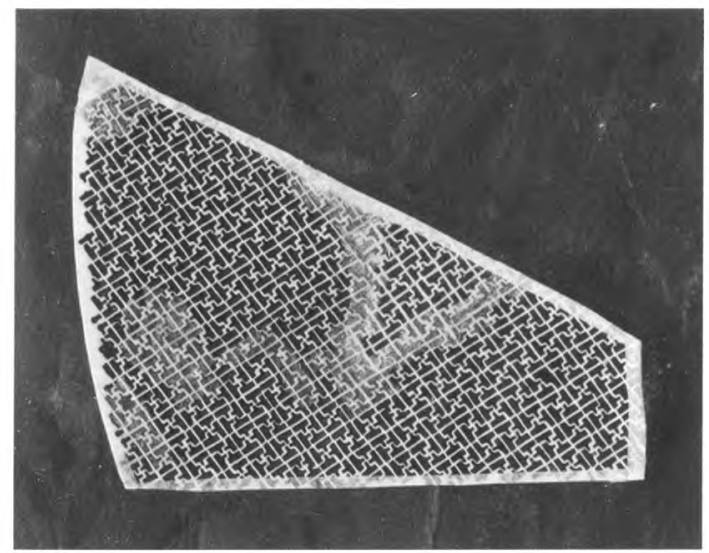

Sterk vergrote foto's ondersteunen dit idee. De sporen van het gereedschap van de ivoorwerker zijn te herkennen. Eerst werd geboord en vervolgens werden de boorgaten bijgevijld tot het patroon de juiste vorm had (afb. 7). Dat dit met uiterste precisie moest gebeuren zal duidelijk zijn, want de doos ontleent de aantrekkelijkheid juist aan de totale gelijkmatigheid van het patroon, aan de perfectie waarmee het is aangebracht.

Het aanvankelijke doel van de behandeling van de dozen was ze geschikt te maken voor fotografie, maar de resultaten waren zo goed dat het paar alsnog werd geselecteerd voor de opstelling in het Nieuwe Rijksmuseum. In een aparte ruimte waar bijzondere en grote collecties van het Rijksmuseum worden getoond - deels bekende zoals Meissen, gegraveerd glas en Kakiemonporselein, deels bijna vergeten zoals sleutels en toverlantaarnplaatjes - komt een grote vitrine met dozen uit alle denkbare materialen en uit alle delen van de wereld. Hier krijgen de 'vazen' van Hans Swarth hun welverdiende plek.

Jan Dorscheid is restaurator. Hij studeerde in Potsdam, Duitsland, liep stage en deed in 2012 zijn afstudeerproject in het Rijksmuseum. Op het moment is hij post-graduate intern in het J. Paul Getty Museum in Los Angeles.

Jan van Campen is conservator Aziatische exportkunst in het Rijksmuseum.

Afbeelding 7 (links) Sterk vergrote opname van een fragment van een paneel in mand AK. NM-7023. De boorsporen (een ronde welving waar het patroon recht had moeten zijn) en het iets te ver doorvijlen zijn zichtbaar

\section{Noot}

1. J. van Campen, 'Masters of the Knife: Chinese carving in wood, ivory and soapstone', The Rijksmuseum Bulletin 59/2 (2011), pp. 152-73. 


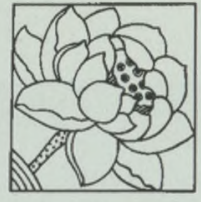

\section{VERENIGING VAN VRIENDEN}

\section{- GROEI}

In het eerste nummer van het belangrijke verenigingsjaar met de opening van het Aziatische Paviljoen in april en de Paviljoendagen in oktober kunnen wij beginnen met verheugend nieuws. De uitbreiding van het gewone lidmaatschap met een partnerlidmaatschap is een succes gebleken, waarmee de gewenste groei van het ledenaantal de goede kant opgaat. Alleen al in de maand januari hebben zich 42 nieuwe leden ingeschreven, waarvan 31 partnerleden!

\section{- AZIATISCH PAVILJOEN}

Op zondag 7 april $\mathbf{2 0 1 3}$ organiseert het Rijksmuseum onder meer voor VVAK-leden aan het einde van de middag een voorbezichtiging van het vernieuwde museum en het Aziatisch Paviljoen. Het paviljoen, gelegen aan de tuin van het Rijksmuseum, is een splinternieuw ontwerp van de Spaanse architecten Cruz en Ortiz. In dit nieuwe gebouw is de prachtige collectie kunst uit China, Japan, Korea, India, Thailand, Vietnam en natuurlijk uit Indonesië, te bewonderen. De 365 voorwerpen uit de periode van 2000 vóór tot 2000 na Christus creëren daar een sfeer van schoonheid, reflectie, magie en verwondering.

\section{- NIEUWJAARSBIJEENKOMST}

Ongeveer honderd leden vonden op 2 februari j.l. de weg naar Keramiekmuseum Princessehof Leeuwarden, waar de nieuwjaarsbijeenkomst 2013 van de VVAK plaatsvond. Geboeid luisterden de aanwezigen naar de nieuwsgierigmakende en kijklustopwekkende lezing Het mysterie Ming van Eva Ströber, conservator Aziatisch keramiek in Princessehof. In de lezing schetste Ströber op knappe wijze het oost-west-thema en de interAziatische dynamiek op het terrein van de verspreiding en handel in porseleinen gebruiksgoederen en het verzamelen van deze objecten van onder anderen Ottema Kingma. De tentoonstelling Het mysterie Ming is in Princessehof te zien van $\mathbf{2 4}$ maart tot $\mathbf{2 7}$ oktober 2013. Het museum presenteert in deze expositie de topstukken uit zijn wereldberoemde keramiekcollectie in een compleet Aziatische ambiance. 